\title{
Volunteer educators bring their own ideas about effective teaching to a 4-H curriculum
}

\author{
Pragmatic and structural constraints shaped the pedagogical choices volunteer educators made, as \\ did their professional identification and comfort with engineering.
}

by Steven Worker

\section{Abstract}

Youth programs implemented during out-of-school time often rely on volunteers. These volunteers are responsible for selecting and adapting curriculum and facilitating activities, so their pedagogical practices become primary contributors to program quality, and ultimately, youth outcomes. To describe volunteers' pedagogical practices, I conducted a qualitative case study at three sites where volunteer educators were implementing a design-based 4-H curriculum. The curriculum advanced youth scientific literacy by supporting scientific inquiry in conjunction with planning, designing and making shareable artifacts. Through detailed observations, videos and focus groups, I identified six common pedagogical practices, though educators differed widely in which ones they used. Pragmatic and structural constraints shaped their choices, as did their professional identification as engineers, or not, and their relative comfort with engineering. To support volunteer educators in implementing a learner-centered educational program, curricula designers might be more specific in recommending and explaining pedagogical practices, and program managers might better train volunteer educators in those preferred practices.

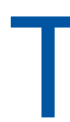
he 4-H Youth Development Program, as well as other out-of-school youth programs, relies heavily on volunteers to extend its reach with youth clientele. Volunteers serve as the direct educator to youth, and thus are often described as the "heart and soul of 4-H” (Radhakrishna and Ewing 2011). Not enough is known about when and how $4-\mathrm{H}$ volunteer educators change their pedagogical practices. The educational value of design-based science teaching, for example, is an emerging pedagogical model (e.g., Apedoe and Schunn 2013); it is learner-centered and has shown success in school environments when facilitated by trained teachers (e.g., Kolodner et al. 2003), but there is limited empirical study of its applicability when facilitated by volunteers.

Adults fulfilling volunteer positions bring diverse experiences, abilities and values; they "come from all walks of life, bringing varied and rich experiences to the 4-H program" (Radhakrishna and Ewing 2011). Some may identify as a content expert, others with youth development experience, but many lack competence or confidence in implementing a learner-centered educational approach (Chi et al. 2013; Kaslon et al. 2005). Regardless of experience and abilities, volunteers serving in an educator role develop programs, select and adapt curriculum, and facilitate activities (Fritz et al. 2003; White and Arnold 2003); thus their pedagogical practices

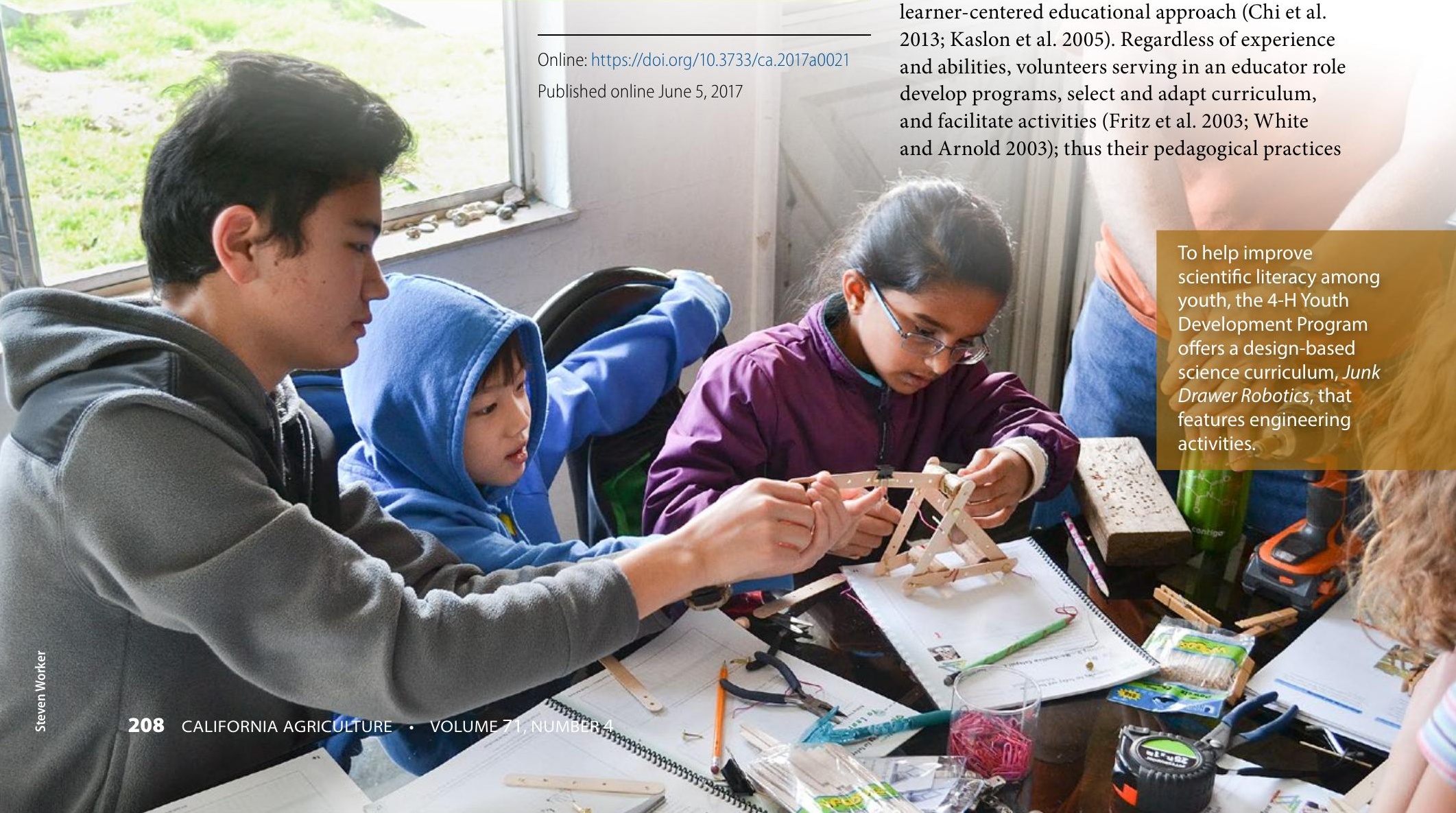


become primary contributors to program quality and, ultimately, youth outcomes.

While the literature on volunteer educator pedagogical practices is broad, varied and incomplete, researchers agree the volunteer educator role is complex and has a significant influence on the structure of the learning environment (Borden et al. 2011; Evans et al. 2012). Furthermore, there is evidence to suggest that volunteer educators often fall back on didactic teaching strategies (Patrick 2017). Volunteer development would improve competence and confidence, but the 4-H program has not offered comprehensive preparation; instead, it has offered volunteers one-time, short-duration events, typically face-to-face, led by an expert (Smith and Schmitt-McQuitty 2013), which are generally considered ineffective in improving practice (Penuel et al. 2007).

\section{Science inquiry + engineering design}

Improving scientific literacy requires effective pedagogical models that support open-ended problemsolving and science learning, broadly referred to as learner-centered educational approaches (NRC 2000). Design-based science is a learner-centered pedagogical model gaining recognition; it integrates science inquiry with engineering design (e.g., Apedoe and Schunn 2013; Fortus et al. 2004; Kolodner et al. 2003; Roth 2001).

Science inquiry is a process of exploration where one poses a question, conducts experiments, collects and interprets data, and communicates findings; it places youth as active agents in their own learning through the practices of science (Lazonder and Harmsen 2016). Design is a process of planning and making in order to accomplish a goal to satisfy requirements subject to constraints (e.g., Dym and Little 2009). Specifically, design-based science engages students in science learning through a design process that involves the planning, designing and making of shareable artifacts. Educators facilitate a sequence of instruction grounded in an engineering design process.

\section{Improving scientific literacy}

Scientific literacy is an important educational goal (NRC 2009a, 2012; UC ANR 2009). Young people in the United States are maturing into a society that has complex challenges. Competency in science, technology, engineering and mathematics (STEM) may help them engage in important issues around economic well-being, public health, the environment and energy conservation (National Academies 2007). These are issues requiring creative and collaborative problem solvers who are highly literate in science and engineering (NRC 2012).

STEM education has become a national emphasis, both in and out of school (NRC 2009a, 2009b).
It's a core part of UC ANR's 4-H Youth Development Program, the UC ANR Strategic Vision 2025 and the California 4-H STEM Initiative.

Design-based science, which originated from research in the K-12 school environment, has shown promise in improving students' content knowledge (Kolodner et al. 2003) and interest in science and engineering careers (Mehalik et al. 2008). Furthermore, research has demonstrated that students gain STEM content knowledge with design-based science methods equal to or greater than with didactic science teaching methods (Mehalik et al. 2008; Silk et al. 2009).

As with most teaching, and particularly in learnercentered educational approaches, the educator serves a prime role in affording and/or constraining opportunities for youth to participate, learn and ultimately improve their scientific literacy. Thus, the educator's abilities to facilitate design-based science are of critical importance.

\section{Study of volunteer educators}

The 4-H Youth Development Program places a heavy reliance on volunteers to facilitate science education. To support the goal of improved scientific literacy, the program needs to recognize how volunteers understand, adapt and implement a curriculum, and their use of various teaching methods (e.g., pedagogical practices such as facilitation and questioning strategies, and interaction with learners). The purpose of this qualitative case study at multiple sites was to describe volunteer educators' pedagogical practices as they implemented a 4-H design-based science curriculum. The specific research questions addressed were: What are the pedagogical practices employed by volunteer educators? What explanations do volunteer educators provide for these practices?

The research context was three 4-H Junk Drawer Robotics (Mahacek et al. 2011) projects organized by adult 4 - $\mathrm{H}$ volunteers in three California counties (sites A, B and C). Junk Drawer Robotics is a peer-reviewed, design-based curriculum providing a sequence of science inquiry activities followed by engineering design challenges. Noncompetitive design activities invite youth to design, build and test artifacts using common items (e.g., paper clips, rubber bands, craft sticks, tubing and syringes), with multiple solution pathways.

The study involved observing the $4-\mathrm{H}$ volunteer educators and youth over an extended period as the volunteer educators
In the design and build participation structure, volunteer educators presented youth with a design challenge and asked them to design and build a device, such as the arm/gripper shown here, to solve the problem. Educators used a variety of teaching techniques for design and build, including targeted questions and offering specific design suggestions.

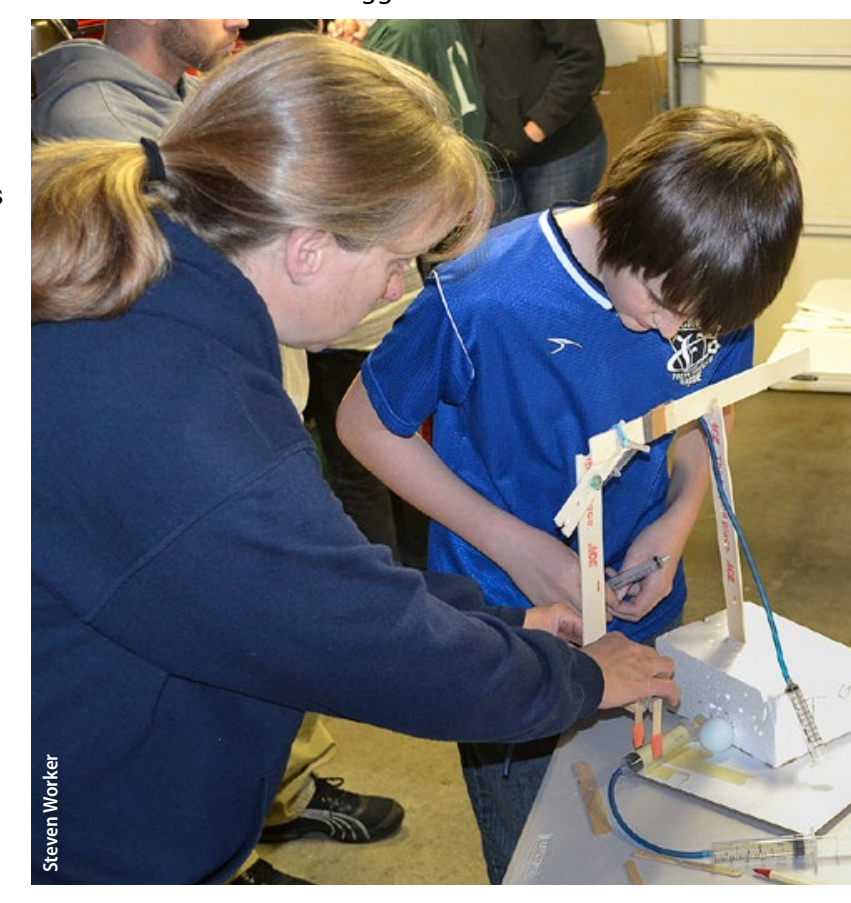


I observed the educator issuing instructions, monitoring progress and demonstrating and/or teaching youth how to use any tools required in the activity. The scripted build was specific to site $\mathrm{C}$, and not tied to the curriculum.

\section{Time spent in participation structures}

I calculated the amount of time spent in each participation structure over time by site (fig. 1). The amount varied, with site B dedicating the most time (81\%) to design and build, site A dedicating much less time (46\%) to design and build, and site $\mathrm{C}$ dedicating the least time (11\%) to design and build but more time to scripted build (31\%, only site C offered scripted build) and learning activities (33\%). Site $\mathrm{C}$ allocated the most time to lecture (22\%). Site A spent more time in group sharing and reflection (22\%) than the other sites.

The 4-H Junk Drawer Robotics curriculum includes only three of the six participation structures - learning activity (nonbuild), group sharing and reflection, and design and build. It does not include instructions or recommendations for lecture, demonstration or scripted build. These three participation structures were introduced by the educators.

To review: participation structures afford and/or constrain opportunities for youth to participate and learn. While a full discussion of youth learning is outside the scope of this paper (but see Worker 2016), it is significant that the three participation structures the educators introduced - lecture, demonstration and scripted build - emphasized STEM content learning. The other three participation structures, those that were in the curriculum - learning activity, sharing and reflection, and design and build - afforded a broader range of learning outcomes, such as deepening engagement in design practices, offering opportunities to manifest resilient, playful and reciprocal dispositions, and developing psychological ownership.

\section{Patterns in pedagogical practices}

I interviewed educators to explore how they rationalized implementing various participation structures. Two key findings surfaced: educators were dealing with pragmatic and structural constraints, and their identification and comfort with engineering shaped their practice.

\section{Practical and structural constraints}

Volunteer educators adapted their teaching practices to the structural constraints of the sites. There were many constraints, including time limitations for the program meetings, voluntary youth participation and frequent absences, and a wide range of youth ages. Educators adapted to voluntary participation by ensuring meetings were fun. They spoke frequently about voluntary participation in relation to their pedagogical practices:
Sawyer: Because this still has to be fun. As much as I love teaching engineering and being excited about this stuff we're doing, if it's not fun the kids won't be back. (Interview, site C, Oct. 13, 2014.)

Educators at the other two sites also recognized this practical constraint of voluntary participation that is, youth may not return if they are not enjoying themselves. The nature and definition of fun was seen as hands-on activities. The meaning of hands-on, however, differed. At site $\mathrm{C}$ and site $\mathrm{A}$, educators used the term hands-on to indicate a fun method that reinforced engineering learning after concepts were introduced. The nature of the hands-on experience was in service of the engineering concept. In contrast, the educators at site B shared their meaning of hands-on as being important to tinkering creative problem-solving emphasizing open-ended design (Bevan et al. 2014), or learning by playing with the materials.

Maintaining youth engagement and interest was often seen as so crucial that educators felt they Two key findings surfaced: educators were dealing with pragmatic and structural constraints, and their identification and comfort with engineering shaped their practice. had to make compromises to maintain the fun. One of the consequences was unplanned activities, like site C's scripted builds, that preserved hands-on fun but at the expense of affording youth opportunities to engage in design practices, exhibit resiliency or improve feelings of ownership. Not all adaptations made by educators were detrimental to learning; for example, at site $\mathrm{C}$, the educator adapted a curriculum activity that involved craft sticks to help youth understand the concepts of lever, balance and fulcrum and built instead a full-sized teeter-totter.

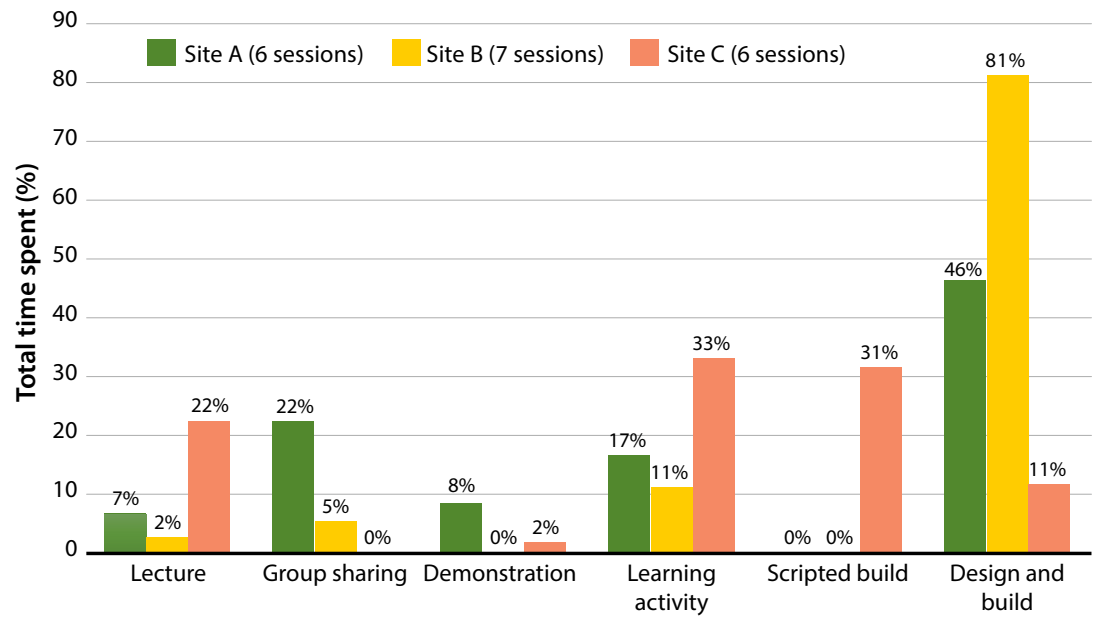

Fig. 1. Percentage of total time volunteer educators spent in each participation structure, by site. The amount of time educators allocated for each participation structure was associated with their ideas and values about teaching - for instance, site B educators who prioritized hands-on tinkering spent more time on the design and build structure than they did on lecture and demonstration. 


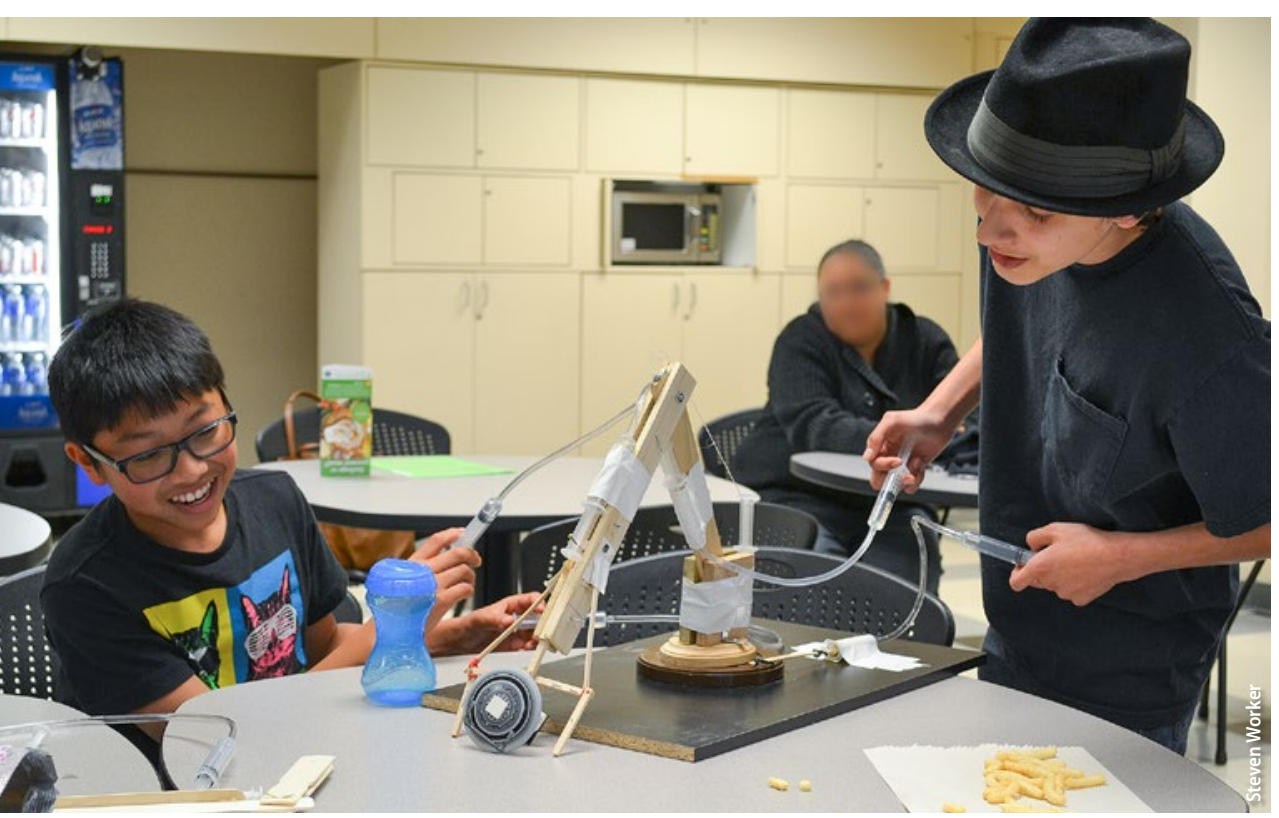

The Junk Drawer Robotics curriculum included a group sharing participation structure in which youth showed their finished devices to their peers. The study found that volunteer educators adapted their teaching practices depending on practical constraints, such as voluntary youth participation, and whether they self-identified as engineers.

\section{Identification, comfort with engineering}

Educators' identification with a professional engineering community was associated with their pedagogical practices. Educators' instructional practices, and the time allocated for participation structures, were related to their knowledge of the concepts, value they placed in engineering practices, and having been socialized into engineering culture. Educators who self-identified as professional engineers were better able to articulate learning objectives that connected to professional practice, and their pedagogical practices more closely aligned with realizing those learning objectives.

I probed into educators' ideas and values about teaching and learning. I associated site $\mathrm{C}$ educator's prioritizing engineering as his learning objective for youth participants with the time he devoted to lecture (22\%), and his interest in making may have been connected to his use of scripted build time (31\%). The site A educator valued group sharing, which was reflected in the time he designated to share and reflect (22\%). In contrast, at Site B two of the three educators did not identify as engineers (the third identified as a computer science student) and they prioritized tinkering and teamwork as their goals, and their pedagogical practices aligned more closely with time for youth to design, build and test in small groups (81\%).

The two educators who identified as engineers, Sawyer and Eugene, did not believe that the final artifact, designed and built by youth, was evidence of learning. Rather, they wanted youth to understand engineering fundamentals, so they reported intentionally structuring meetings so they could share information before youth began to design and build. Sawyer stated, "You have to learn the fundamentals first" (interview, site C, May 4, 2015). Eugene reported his meetings "naturally progressed to a lecture style thing for a little bit and then some discussion and ... then we wanted to build something" (interview, site A, Apr. 2, 2014).
One youth wanted less talking and more building, to which Eugene responded, "I think in the very beginning if I didn't talk a lot it would be difficult for you, in my mind, to start working" (field note, site A, Mar. 26, 2015).

In contrast, one educator who did not identify as an engineer most valued hands-on design experience, for its value in the service of tinkering:

Robin: I'm a hands-on learner. ... some of today's youth are the same way. They have to do it to physically learn it, and that's how I am. So I like to tinker and play with stuff. (Interview, site B, Jun. 22, 2015.)

In general, educators who identified as professional engineers, having been socialized into an engineering way of thinking, allocated more time for lecture, demonstration, learning activities and scripted build than to design and build. They chose participation structures that were oriented toward information sharing, where youth could learn fundamental engineering concepts first and then have it reinforced in hands-on activity.

\section{Curriculum design, educator training}

Volunteer educators bring with them their own notions about effective teaching, their own interests and values, and through their pedagogical practice, afford and constrain opportunities for youth to participate and learn. One lesson learned from this study is that volunteer educators make adaptations. The adapted activities may inadvertently constrain, or alternatively strengthen, pathways for youth to participate. Without intentionality on the part of the educator, youth may not reach the intended learning objective outlined by the curriculum.

Other lessons learned from this study involve the development of curricula and professional development. Curriculum designers may need to make more explicit the core functional elements that contribute to the desired learning outcomes (Olson et al. 2015). Specifically, the curriculum should outline its learning objectives and link them clearly to participation structures. For example, a curriculum using group sharing and reflection should explain the intended learning outcome, include a rationale for its importance, tips for successful implementation and ideas to informally evaluate learning outcomes.

Program managers may need to target their recruitment and training to address the internal values, interests and identity that volunteer educators bring with them. As evidenced in the findings, those who identified with a professional field that was related to the subject matter had preconceived ideas about effective pedagogical models, even when the curriculum incorporated a distinct pedagogical model. One potential solution is to focus on expanding volunteer 
educators' conception of learning to include not only STEM-specific concepts, but also how to improve youth engagement, dispositions and ownership. This might allow educators to see connections between the activity structures and how they afford or constrain learning outcomes.

\section{Educational research}

As this qualitative multiple-case study demonstrates, identifying emerging patterns of discourse and activity - participation structures - led to fruitful cross-site comparisons of pedagogical practices. This technique, grounded in sociocultural perspectives of learning, may be applied to other learning environments resulting in meaningful descriptions of practice. CA

S. Worker is UC Cooperative Extension 4-H Youth Development Advisor in Marin, Sonoma and Napa counties.

l extend my appreciation to Cynthia Carter Ching, Lee Martin and Tobin White for their guidance on the dissertation research from which this article was developed.

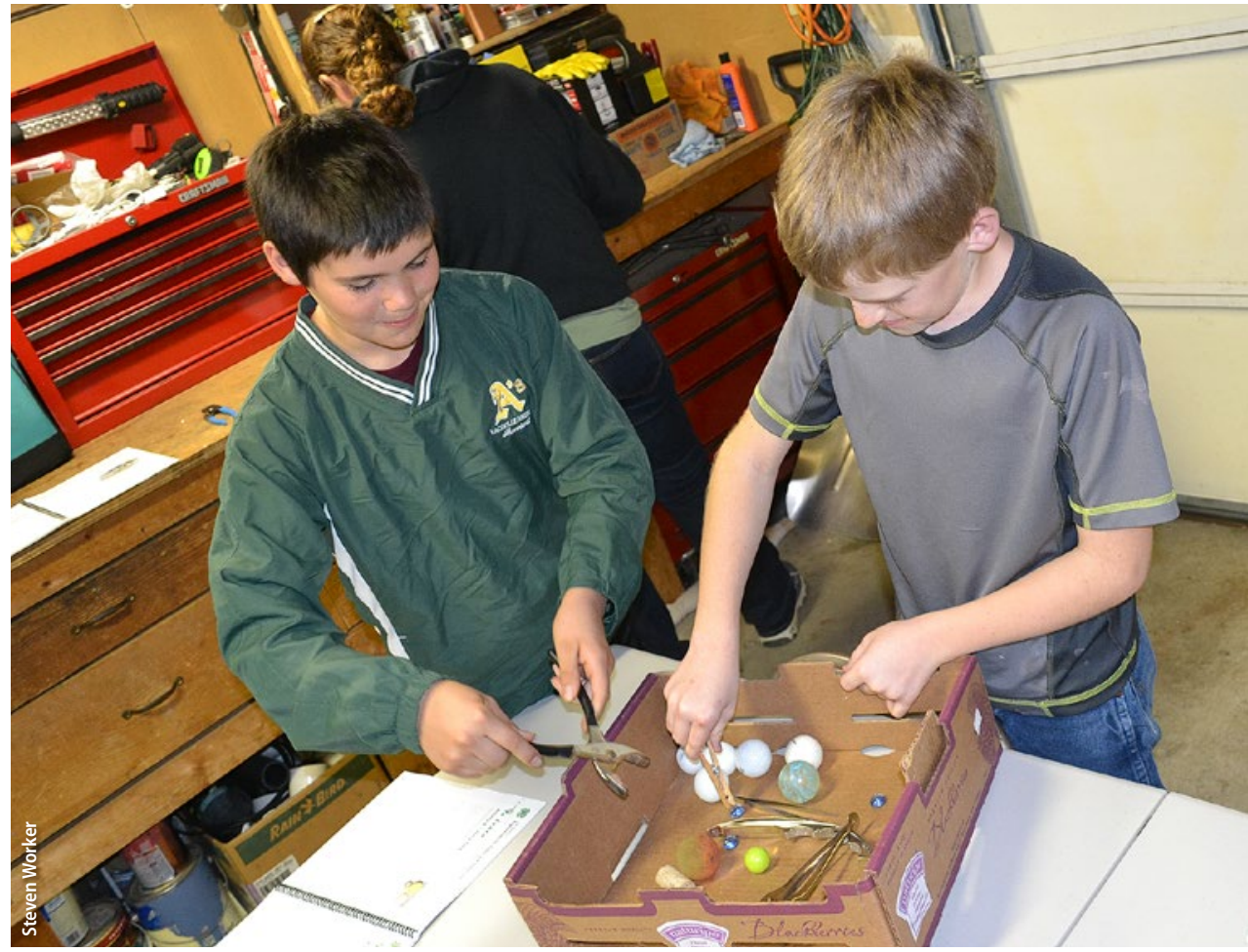

Before adding grippers to their devices, youth experiment with picking up balls with different types of grippers (learning activity participation structure).

\section{References}

Apedoe XS, Schunn CD. 2013. Strategies for success: Uncovering what makes students successful in design and learning. Instr Sci 41(4):773-91.

Bevan B, Gutwill JP, Petrich M, Wilkinson K. 2014. Learning through STEM-rich tinkering: Findings from a jointly negotiated research project taken up in practice. Sci Educ 99(1):98-120.

Borden LM, Schlomer GL, Wiggs CB. 2011. The evolving role of youth workers. J Youth Dev 6(3):126-38.

Chi B, Wierman T, Stuart K. 2013 Examining potential effects of afterschool KidzScience curriculum and professional development resources on youth and instructors. In: Proc Ann Mtg Amer Educ Res Assoc, April 2013. San Francisco, CA

Dym CL, Little P. 2009. Engineering Design: A Project-Based Introduction (3rd ed.). Hoboken, NJ: John Wiley \& Sons, Inc.

Evans E, Carter Ching C, Ballard H. 2012. Volunteer guides in nature reserves: Exploring environmental educators' perceptions of teaching, learning, place and self. Environ Educ Res 18(3):391-402.
Fortus D, Dershimer RC, Krajcik J, et al. 2004. Design-based science and student learning. J Res Sci Teach 41(10):1081-110.

Fritz S, Karmazin D, Barbuto J, Burrow S. 2003. Urban and rural 4-H adult volunteer leaders' preferred forms of recognition and motivation. J Extension 41(3).

Greeno JG. 2006. Learning in activity. In: Sawyer RK (ed.). The Cambridge Handbook of the Learning Sciences. New York: Cambridge University Pr. p 79-96.

Jordan B, Henderson A. 1995 Interaction analysis: Foundations and practice. J Learn Sci 4(1):39-103.

Kaslon L, Lodl K, Greve V. 2005. Online leader training for $4-\mathrm{H}$ volunteers: A case study of action research. J Extension 43(2).

Kolodner JL, Camp PJ, Crismond D, et al. 2003. Problem-based learning meets case-based reasoning in the middle-school science classroom: Putting learning by design into practice. J Learn Sci 12(4):495-547.

Krueger RA, Casey MA. 2015 Focus Groups: A Practical Guide for Applied Research (5th ed.) Thousand Oaks, CA: Sage.

Lazonder AW, Harmsen R. 2016. Meta-analysis of inquiry-based learning: Effects of guidance. Rev Educ Res 86(3).
Mahacek R, Worker S, Mahacek A. 2011.4-H Junk Drawer Robotics Curriculum. Chevy Chase, MD: National 4-H Council.

Mehalik MM, Doppelt Y, Schunn CD. 2008. Middle-school science through design-based learning versus scripted inquiry: Better overall science concept earning and equity gap reduction. J Eng Educ 97(1):71-85.

Merriam SB, Tisdell EJ. 2016.

Qualitative Research: A Guide to Design and Implementation (4th ed.). San Francisco: Jossey-Bass.

National Academies. 2007. Rising Above the Gathering Storm: Energizing and Employing America for a Brighter Economic Future. Washington, DC: $\mathrm{Na}$ ional Academies Pr.

[NRC] National Research Council. 2000. How People Learn: Brain, Mind, Experience, and School. Washington DC: National Academies Pr.

NRC. 2009a. Learning Science in Informal Environments: People,

Places, and Pursuits. Washington DC: National Academies Pr.

NRC. 2009b. Engineering in K-12 Education: Understanding the Status and Improving the Prospects. Washington, DC: Nationa Academies Pr.
NRC. 2012. A Framework for K-12 Science Education: Practices, Crosscutting Concepts, and Core Ideas. Washington, DC: National Academies Pr.

Olson JR, Welsh JA, Perkins DF. 2015. Evidence-based programming within Cooperative Extension: How can we maintain program fidelity while adapting to meet local needs? J Extension 53(3). Article \#3FEA3.

Patrick P (ed.). 2017. Preparing Informal Science Educators: Perspectives from Science Com-

munication and Education. New York, NY: Springer.

Penuel WR, Fishman BJ, Yamaguchi R, Gallagher LP. 2007 What makes professional development effective? Strategies that foster curriculum implementation. Am Educ Res 44(4):921-58.

Radhakrishna R, Ewing JC. 2011 Relationships between 4- $\mathrm{H}$

volunteer leader competencies and skills youth learn in 4-H pro grams. J Extension 49(4).

Roth W-M. 2001. Learning science through techno-

logical design. J Res Sci Teach 38(7):768-90

Seidman | 2013. Interviewing as Qualitative Research: A Guide for Researchers in Education and the Social Sciences (4th ed.). New York, NY: Teachers College Pr.
Silk EM, Schunn CD, Cary MS. 2009. The impact of an engineering design curriculum on science reasoning in an urban setting. J Sci Educ Technol 18(3):209-23.

Smith MH, Schmitt-McQuitty L. 2013. More effective professional development can help 4-H volunteers address need for youth scientific literacy. Calif Agr 67(1):54-61.

[UC ANR] UC Agriculture and Natural Resources. 2010. Healthy Families and Communities Strategic Plan http://ucan edu/sites/Strategic/nitiatives/ files/202847.pdf.

Vadeboncoeur JA. 2006. Engaging young people: Learning in informal contexts (Ch. 7). Re Res Educ 30(1):239-78.

White DJ, Arnold ME. 2003. Why they come, why they go, and why they stay: Factors affecting volunteerism in 4-H programs. Extension 41(4).

Worker SM. 2016. Volunteer Educators' Influence on Youth Participation and Learning in 4-H STEM Learning by Design Programs. Doctoral dissertation, School of Education, UC Davis, CA. PQDT Open ISBN 9781369201710. 